\title{
O impacto da organização do trabalho na saúde mental: um estudo em psicodinâmica do trabalho
}

\section{The work organization impact at the mental health: a phsycodynamic study}

\author{
Selma Lancman', Tatiana Andrade Jardim²
}

\begin{abstract}
LANCMAN, S.; JARDIM, T. A. O impacto da organização do trabalho na saúde mental: um estudo em psicodinâmica do trabalho. Rev. Ter. Ocup. Univ. São Paulo, v. 15, n. 2, p. 82-9, maio/ago., 2004.
\end{abstract}

\begin{abstract}
RESUMO: A partir dos princípios teóricos e metodológicos da psicodinâmica do trabalho, este estudo procura analisar o impacto do trabalho na saúde mental dos Técnicos de Controle de Tráfego da Central de Operações da Companhia de Engenharia de Tráfego do Município São Paulo. Para tanto, procuramos a partir da realização de grupos de reflexão sobre o trabalho e da ampliação do espaço público de discussão, desvendar aspectos subjetivos que pudessem estar gerando elevados níveis de sofrimento e de adoecimento. Entre os resultados pudemos encontrar diversas situações de falta de reconhecimento no trabalho, necessidade de tomada de decisões de grande impacto no tráfego, de forma improvisada sem autonomia e sem o conhecimento global da situação na qual deveriam intervir e ruptura de mecanismos de cooperação.
\end{abstract}

DESCRITORES: Saúde mental. Trabalho/psicologia. Psicologia do trabalho. Terapia Ocupacional.

\section{INTRODUÇÃO}

$\mathrm{O}$ processo de globalização econômica atualmente em curso tem definido, intensas transformações no mundo do trabalho. As inovações tecnológicas, o enfraquecimento da atividade econômica, as mudanças na organização do trabalho, e a incorporação crescente do trabalho feminino são alguns dos fatores que vêm contribuindo para que haja uma redefinição das relações entre capital e trabalho (LANCMAN; UCHIDA, 2003).
No Brasil, por suas características de desenvolvimento e por sua maior vulnerabilidade às variações da economia internacional, os efeitos da globalização e destas novas formas de organização do trabalho foram ainda mais perversos. Todas estas mudanças ocorreram, sem que tivéssemos atingido, anteriormente, um estágio de formalização e de direitos sociais equivalente ao dos países desenvolvidos.

A deterioração e a precarização das condições de

\footnotetext{
${ }^{1}$ Docente do Departamento de Fisioterapia, Fonoaudiologia e Terapia Ocupacional da Faculdade de Medicina da Universidade de São Paulo.

${ }^{2}$ Bolsita do LIIST - Laboratório de Investigação e Intervenção em Saúde e Trabalho do Curso de Fisioterapia, Fonoaudiologia e Terapia Ocupacional da Faculdade de Medicina da USP.

Endereço para correspondência: Departamento de Fisioterapia, Fonoaudiologia e Terapia Ocupacional da Faculdade de Medicina da Universidade de São Paulo. Rua Cipotânea, 51. CEP 05360-000. São Paulo, SP.
} 
trabalho, o aumento do desemprego e a restrição de direitos atinge, também, o trabalho daqueles que ainda estão empregados. Os assalariados terminam cedendo às perdas de direitos trabalhistas e previdenciários e aos mecanismos de proteção e fiscalização em relação à saúde, expondo-se mais aos riscos de adoecimento e acidente de trabalho. A perda do poder de barganha de quem procura emprego leva os trabalhadores a ter que escolher entre um mau trabalho ou trabalho nenhum (LANCMAN; GHIRARDI, 2002). Entender esta precarização do trabalho é importante para perceber a realidade subjetiva vivida pelos trabalhadores que são obrigados a conviver em um mundo onde se perdeu uma série de garantias e direitos, de conquistas que protegiam social e psiquicamente as pessoas (LANCMAN; UCHIDA, 2003).

Exige-se do trabalhador um aumento da produtividade que é alcançado através da intensificação do ritmo de trabalho. Esta intensificação desconsidera a variabilidade do ritmo, os aspectos anatômicos, fisiológicos e cognitivos humanos. As relações de trabalho são cada vez mais competitivas e destroem processos de cooperação e relações de confiança e solidariedade que protegiam psiquicamente as pessoas. Termina prevalecendo o individualismo, o "cada um por si”. Esta situação é vista pelos trabalhadores como inerente às atividades e necessária à manutenção dos empregos (DEJOURS, 2000).

As exigências excessivas do trabalho levam a um desgaste precoce tanto físico quanto psíquico. O trabalhador, para manter seu desempenho e a produtividade, sobrecarrega seu organismo ficando mais vulnerável a quadros de adoecimento. Os distúrbios osteomusculares e as lesões por esforços repetitivos DORT/LER, além dos transtornos psíquicos, são hoje as principais causas de afastamento no trabalho e de aposentadorias precoces, com forte impacto nas contas do sistema previdenciário.

\section{MUDANÇAS NO TRABALHO E SEUS REFLE- XOS NO ESPAÇO URBANO}

As mudanças no mundo moderno refletem-se também no espaço urbano, obrigando os moradores a aumentar seus deslocamentos cotidianos tanto em número quanto em distância. Em São Paulo, este fato é agravado pelo crescimento desordenado da metrópole, pela falta de uma política que garanta transporte coletivo de qualidade e pelo aumento da frota urbana e do número de automóveis por habitantes. O sistema viário em São Paulo passou por uma grande transformação nos últimos anos, havendo diversas ampliações, tais como: aumento de faixas expressas, alargamentos e prolongamentos de vias arteriais, incorporação de novas vias, etc. No entanto, este crescimento não melhorou as condições de trânsito da cidade, pois os investimentos em infra-estrutura urbana e no gerenciamento do trânsito, não acompanharam o crescimento da cidade nem o aumento da frota.

A Companhia de Engenharia de Tráfego (CET) foi criada em 1976 com os objetivos de planejar e implantar a operação do sistema viário e assegurar maior segurança e fluidez do trânsito; promover a implantação e a exploração econômica de equipamentos urbanos, de modo a melhorar as condições do tráfego; prestar serviços ou executar obras relacionadas à operação do sistema viário além da implantação e manutenção da sinalização. A saturação quase permanente do sistema viário torna estratégica a ação da CET. Para tanto, a Empresa contava, em 2002, com cerca de 3600 funcionários, $48 \%$ dos quais destinados à operação e o restante distribuído nas áreas de sinalização, administração, projetos, educação e finanças.

A Central de Operações tem, entre as suas responsabilidades, minimizar os problemas de fluidez, pela operacionalização e intervenção no trânsito e monitorar, por rádios de comunicação, todas as informações geradas pelas equipes operacionais de rua, administrando as ocorrências e dando os devidos encaminhamentos, seja interno ou externo à Companhia. Com a expansão da Empresa e a descentralização da operação em Gerências regionais a Central deixou de, prioritariamente, operar o trânsito, passando a acompanhar as ações e a receber as informações e encaminhá-las. A Central possuía na época 124 trabalhadores, dos quais $53 \%$ operavam o sistema de rádio.

A missão de "dar fluidez ao trânsito" é uma meta quase impossível de ser realizada frente aos recursos disponíveis e aos problemas da cidade, cabendo à CET, sobretudo, "desobstruir" intercorrências que poderiam agravar ainda mais a circulação de veículos.

Apesar de todas estas dificuldades, o sistema funciona, os trabalhadores não medem esforços para não paralisá-lo. Há um investimento intenso no trabalho, em fazê-lo acontecer. Esse engajamento e empenho na sua realização potencializa uma série de mecanismos que impulsionam os trabalhadores, mas, de outro, gera grande sofrimento psíquico. O comprometimento dos trabalhadores com o trabalho faz com que busquem fazê-lo com uma qualidade que, apesar dos seus esforços, nem sempre alcança os resultados, a qualidade e o reconhecimento equivalente ao investimento e ao envolvimento realizado. 


\section{TRABALHOESAUDEMENTAL}

O campo da Saúde Mental e Trabalho estuda as inter-relações entre o trabalho, os processos de adoecimento psíquico e o impacto dos aspectos subjetivos do trabalho na saúde mental dos indivíduos. A aproximação entre campos tão diferentes implica relacionar disciplinas teóricas e dialogar com diferentes abordagens, que partem de epistemologias diversas e que, por sua vez, não compreendem da mesma forma o indivíduo, a sociedade, as relações entre corpo e mente e, principalmente, as relações entre os indivíduos e o trabalho como determinantes da saúde mental.

Entre as diversas disciplinas que buscam refletir sobre as relações entre a saúde/doença mental e o trabalho destacamos a Psicodinâmica do Trabalho (PDT) por considerarmos a teoria que mais desenvolveu reflexões sobre os aspectos psíquicos e subjetivos mobilizados nas relações e na organização do trabalho e pela reconhecida contribuição destas produções para a construção desse campo, em especial, da escola francesa e do pensamento de Christophe Dejours.

A partir de pesquisas em Psicopatologia do Trabalho, Dejours (2004a) observou que, por vezes, os trabalhadores não desenvolverem um número maior de patologias mentais, mesmo diante das condições patogênicas de trabalho às quais estão submetidos. Surpreendeu-se, ainda, com o fato de que os indivíduos que trabalham tendem a estar em melhores condições psíquicas do que aqueles que não trabalham. Esta constatação levou-o a ampliar seu eixo de investigação para o campo da normalidade. É a essa nova disciplina - que vai buscar compreender a complexidade das relações psíquicas envolvidas no processo de trabalho - que ele denomina de Psicodinâmica do Trabalho (DEJOURS, 2004a).

Uma das constatações destas pesquisas foi que os trabalhadores desenvolvem um conjunto de estratégias defensivas, individuais e coletivas, para se protegerem dos constrangimentos psíquicos impostos pelo trabalho. A normalidade surge como resultado de uma dinâmica entre o sofrimento e as defesas contra o mesmo. Este sofrimento não se manifesta porque os sujeitos conseguem se proteger e se defender. A patologia surge quando se rompe o equilíbrio, e o sofrimento não é mais suportável. Em outros termos, ela surge quando o trabalhador utilizou todos os seus recursos intelectuais e psico-afetivos para lidar com as atividades e demandas impostas pela organização e percebe que nada pode fazer para se adaptar e/ou transformar o trabalho (LANCMAN; UCHIDA, 2003).

A partir de investigações em situações concretas de trabalho, a Psicodinâmica do Trabalho vem formulando novos conceitos teóricos de fundamental importância para se entender a função psíquica do trabalho e sua relação com a organização do trabalho, entre elas: mecanismos de cooperação, estratégias de defesa individuais e coletivas ligadas ao trabalho, visibilidade, valorização e reconhecimento, cooperação, sofrimento psíquico e mobilização da inteligência.

$\mathrm{O}$ trabalho permite o confronto entre mundo externo e mundo interno do trabalhador. $\mathrm{O}$ mundo objetivo, com suas lógicas, seus desafios, suas regras e seus valores, vai entrar em conflito com a singularidade de cada trabalhador, fazendo com que o confronto entre, de um lado, relações e organizações do trabalho e, de outro, mundo interno e subjetivo do trabalhador sejam geradores de sofrimento psíquico. Há um desacordo entre a lógica das empresas, voltada para o lucro e para a produtividade e que entende os homens como peças de engrenagem e a lógica do indivíduo, que é contraditório, tem angústias, desejos, medos e busca manter sua saúde mental em meio a essa complexidade de relações.

O trabalho é gerador de sofrimento, na medida em que confronta as pessoas com desafios externos, mas também é a oportunidade central de crescimento e de desenvolvimento psicossocial do adulto. Se o trabalho leva ao sofrimento e ao adoecimento, ele se constitui numa fonte de prazer e de desenvolvimento do indivíduo. O trabalho e as relações que nele se originam nunca podem ser tomados como um espaço de neutralidade subjetiva ou social (BANDT et. al., 1995; LANCMAN; SZNELWAR, 2004a).

Entender a influência da organização do trabalho na qualidade de vida, na saúde mental, no desgaste e no adoecimento dos trabalhadores é fundamental para a compreensão e para a intervenção em situações de trabalho que podem levar a diversas formas de sofrimento, adoecimento e exclusão.

Frente ao exposto objetivaremos neste artigo o estudo de uma situação concreta de trabalho para compreender os aspectos que estejam gerando sofrimento psíquico e/ou agravos à saúde destes trabalhadores visando não apenas colaborar na transformação e melhoria das condições deste trabalho e em sua organização, mas também compreender os mecanismos geradores destes agravos e sofrimento e seu nexo com o trabalho e aprofundar a compreensão das conseqüências da organização do trabalho na saúde mental dos trabalhadores buscando fazer avançar teorias que ajudem a explicar outros espaços produtivos e que sejam aplicáveis a outros contextos e situações de trabalho. 


\section{MÉTODOSE PROCEDIMENTOS}

Compreender as relações de trabalho exige mais do que a simples observação. Exige, sobretudo, uma escuta voltada para quem executa o trabalho, pois este implica em relações subjetivas menos evidentes e que precisam ser desvendadas. Para apreender o trabalho em sua complexidade, é necessário entendê-lo e explicálo para além do que pode ser visível e mensurável. É necessário que se considere a qualidade das relações que ele propicia. A escuta proposta pela PDT é realizada de forma coletiva, por meio de um processo de reflexão com um conjunto de trabalhadores. É somente a partir da reflexão sobre o próprio fazer que o indivíduo é capaz de se reapropriar da realidade de seu trabalho gerando a mobilização necessária para impulsionar as mudanças e tornar esse trabalho mais saudável Dejours (1994).

O método preconizado em PDT é construído a partir de uma série de etapas que servem de norteadores para o trabalho de campo (DEJOURS, 2004). Apesar dessas etapas serem fundamentais para o alcance dos objetivos propostos, entendemos que cada enquête e cada situação de trabalho é peculiar e envolverá algumas adaptações, que, no entanto, não devem comprometer a integridade do método. Conforme já descrito em diversas publicações o método é composto pelas seguintes etapas: 1) a construção do estudo: a préenquete; 2 ) a enquete, que é subdividida em análise da demanda, análise do material da enquête, a observação clínica e a interpretação; 3) validação e refutação e validação ampliada (DEJOURS, 2004b).

Segundo o método apresentado foram realizadas 8 sessões grupais que contaram com a participação de 10 trabalhadores representantes dos vários turnos de trabalho. A pesquisa foi apresentada inicialmente ao conjunto dos trabalhadores e alguns deles, segundo o critério de voluntariado, se candidataram a participar dos grupos. Após o término das sessões foi elaborado um relatório que após validação com o grupo foi discutido em sessões de validação ampliada com trabalhadores de postos correlatos (LANCMAN, 2002).

Entre os postos de trabalho da Central este estudo se ateve ao Posto responsável pelo monitoramento do trabalho de campo, realizado pelos Técnicos de Controle de Tráfego - TCTs. Esses trabalhadores através da operação do Sistema de Rádio Comunicação são responsáveis por coordenar ações, como, estabelecer rotas alternativas, quando ocorrem obras ou acidentes que obstruem o trânsito; remoção de interferências, pelo acionamento de guinchamentos, de viaturas e dos Operadores de Tráfego (conhecidos como marronzinhos); monitorar as informações geradas pelas equipes operacionais de rua; administrar e encaminhar as ocorrências sejam elas internas ou externas à Companhia.

\section{RESULTADOS}

A CET, por ser uma empresa ligada ao município, tem seu funcionamento modificado dependendo da administração municipal e, por vezes, há interferências políticas sobre as ações técnicas. Situações mais graves terminam por interferir no trânsito, na vida dos munícipes, geram insatisfações e tornam-se questões políticas. Isso faz com que, durante as ações de maior impacto, os altos escalões da CET e da Prefeitura devam ser comunicados e consultados de forma hierarquicamente prevista. Alguns destes chefes, embora tenham poder, nem sempre subsidiam tecnicamente as intervenções que devem ser realizadas. Não são chefes que orientem e respaldem ações, ou com quem os trabalhadores na Central possam contar (LANCMAN, 2002).

Este alto escalão, por vezes, também não compartilha a responsabilidade quando as ações não ocorrem da forma prevista e acabam gerando grandes engarrafamentos. A falta de um chefe experiente, que, de fato, os oriente e a necessidade de agirem sem estas orientações leva esses trabalhadores a sentimentos de insegurança, medo e solidão. Afinal, com quem partilhar as dúvidas? Com quem dividir as responsabilidades? Com quem partilhar os acertos e erros?

A organização do trabalho os obriga a tomar decisões emergenciais e a realizarem ações para as quais, a rigor, na estrutura organizacional, não têm autonomia. Por vezes, após tomarem estas decisões, necessitam legitimá-las, fazendo com que os chefes autorizem ações que, na verdade, já foram executadas. São também obrigados a assumir responsabilidades sobre ações para as quais não dispõem das informações necessárias, não tendo como avaliar a complexidade do impacto das decisões que devem tomar.

Quando as decisões resultam em ações que facilitam a fluidez do trânsito, elas passam desapercebidas, e eles não recebem nenhum tipo de reconhecimento. No entanto, quando a decisão não soluciona, ou piora os congestionamentos, eles arcam sozinhos com o peso da decisão que tiveram que tomar. Isto os faz sentirem-se moralmente constrangidos, principalmente se a ação na qual intervieram envolvia acidentados que necessitavam de socorro médico.

Com o crescimento da Empresa sem uma definição/ delimitação precisa entre as áreas de abrangência das várias Gerências (GETs) criou-se, no decorrer do tempo, 
uma oscilação uma série de dificuldades no desenvolvimento do trabalho. Isso se reflete no fluxo das informações e no desencadeamento de ações no trânsito, pois os trabalhadores sentem-se excluídos de certas ações e mal informados em outras. Esta situação cria uma série de mal-entendidos, disputas de poder, disputa pelas informações e pelas ações, sentimentos de insatisfação e problemas de relacionamento entre setores.

$\mathrm{Na}$ Central, o que é valorizado é a operação, entretanto, pouco a pouco, parte desta função foi sendo incorporada pelas GETs. Atualmente, a tarefa principal da Central é coordenar as informações que recebem e encaminhá-las. A Central, por ter uma visão mais global dos eventos que atingem a cidade responsabiliza-se, somente, pelas operações que envolvem problemas no trânsito de maior amplitude. Os recursos disponíveis na Empresa não são suficientes para atender a todas as necessidades. Em uma situação onde há várias demandas, cabe à Central, por ter uma visão global, priorizar qual será a área ou o problema a ser atendido.

Um outro aspecto que interfere em toda a Central é o que denominamos de "efeito vitrine". Ele advém da necessidade de manter uma imagem pública de empresa organizada, moderna tecnologicamente e eficiente. Essa imagem deve ser preservada, apesar da existência freqüente de situações adversas, tais como: falta de verbas, interferências políticas, dificuldades na própria missão da empresa, catástrofes na cidade e inoperância de outros órgãos. O "efeito vitrine" é agravado pela presença constante da imprensa, através de emissoras de televisão, de rádios e dos jornais, no local de trabalho. O próprio espaço físico organizado como um aquário, contribui para este efeito.

Esta condição vai criar uma separação muito acentuada entre o trabalho prescrito (aquele que a empresa diz que os trabalhadores devem fazer), o trabalho real (aquele que, de fato, os trabalhadores realizam com os recursos de que dispõem e frente à variabilidade do trabalho) e o "efeito vitrine" (aquele que deve parecer que eles fazem).

A principal conseqüência desse efeito é o excesso de exposição dos trabalhadores e a impossibilidade de dar visibilidade aos erros e contradições existentes no processo de trabalho, dificultando a busca de soluções e a discussão do próprio trabalho. Paradoxalmente, esse processo também dificulta a possibilidade de dar visibilidade aos acertos e aos esforços realizados para cumprir o trabalho. Isso impede que os trabalhadores possam ser reconhecidos pelo que fazem e pelo esforço que realizam, o que contribui para o aumento de seu sofrimento psíquico.

Os TCTs devem, ao escutar as solicitações do pessoal de campo, discriminar, selecionar, filtrar, triar e priorizar as necessidades e demandas e dar o retorno sobre o encaminhamento dado. É comum ocorrerem várias chamadas e demandas ao mesmo tempo e, frente às dificuldades da Empresa em atender a todas simultaneamente, eles são orientados a atender primeiro as chamadas "prioritárias". Os trabalhadores da rua, conhecendo esse procedimento, para verem suas solicitações serem atendidas, costumam utilizar um recurso/macete, que consiste em modificar ou exagerar a importância da informação que devem passar, de forma que essa solicitação seja tratada como uma prioridade. No final, este recurso, utilizado por todos, levou a uma banalização do sentido de prioridade, dificultando a realização do trabalho de todos e exigindo que os TCTs filtrem as demandas e trabalhem com informações super ou subestimadas.

Frente a acontecimentos simultâneos, eles têm que escolher para onde irão os recursos. Atender uma demanda, por vezes, significa deixar de atender outra. Deve-se salientar que envolvem, às vezes, situações de grande tensão, com acidentes de gravidade, que podem provocar sérios impactos no trânsito ou com vítimas fatais. Filtrar estas informações significa ser continente da angústia do trabalhador de campo e informar sobre o não-atendimento das solicitações significa ser alvo da raiva e frustração dos mesmos.

Os vários trabalhadores envolvidos com a operação desconhecem as atribuições e a capacidade operacional da Central e o trabalho por eles realizado: assim, terminam por esperar deles um desempenho que não podem cumprir e atribuem o não atendimento das solicitações à incompetência profissional e não à falta de infra-estrutura da Empresa.

Os TCTs assumiram o papel de "anteparo" entre os operadores de rua e a Empresa. Acabam tendo que representá-la junto a seus trabalhadores e ouvir suas reclamações que são, na verdade, dirigidas à CET. Assumir o papel de 'anteparo' acaba gerando situações de discussões, competição e conflitos entre os trabalhadores e entre as áreas.

Os TCTs reclamam da desconfiança, desvalorização e invisibilidade do trabalho que executam, tanto para as chefias, quanto para o pessoal de campo e os munícipes. Esta invisibilidade parece estar associada à idéia de que o trabalho com o rádio se restringe a registrar e comunicar informações. Embora a importância do posto de trabalho deles seja reconhecida na Central, os esforços, a mobilização e as dificuldades que encontram para realizar seu trabalho não os são.

A forma como o trabalho está organizado, a falta de funcionários e o grande número de afastamentos têm 
favorecido que ocorra uma cotidiana diferença entre a escala prevista para o turno e a necessidade real de pessoal, o que acaba obrigando os trabalhadores a dobrarem o turno com frequiência. Isso implica em 12 horas de trabalho consecutivo. Essa situação termina por adoecê-los, gerando mais afastamentos e faltas, formando um círculo vicioso perverso: sobrecarga/ adoecimentos/faltas/ afastamentos/nova sobrecarga.

A organização do trabalho varia conforme o turno e a chefia responsável por ele. $\mathrm{O}$ fato deles dobrarem e trabalharem simultaneamente em vários turnos, implica em terem de se adaptar a chefias, a equipes de trabalho e a regras e procedimentos de trânsito diferentes, muitas vezes no mesmo dia: chegam a não saber quais regras devem obedecer. Isso também traz uma dificuldade cognitiva adicional, pois o fluxo do trânsito muda conforme o horário, ou seja, o mais intenso segue no sentido bairro-centro de manhã, invertendo-se à tarde. Assim, os TCTs são obrigados a inverter procedimentos e mesmo a compreensão da problemática da operação de trânsito.

\section{DISCUSSÃO}

Para a ergonomia, há sempre uma grande defasagem entre o trabalho prescrito e o trabalho real. O trabalho prescrito é o conjunto de regras e procedimentos que caracterizam o trabalho a ser realizado, ou seja, a maneira como o trabalho deve ser executado: o modo de empregar as ferramentas e o maquinário, o tempo despendido em cada operação, os modos operatórios e as regras. Todas as variabilidades que envolvem o trabalho real, tornam o trabalho tal como é prescrito irrealizável. As falhas estão, em geral, relacionadas à dimensão do trabalho real e, portanto, por vezes, não são previstas, ou levadas em conta no planejamento do trabalho prescrito (DANIELLOU et al., 2004).

A PDT tem apontado, em diversos textos, o hiato existente entre a organização do trabalho prescrito e a organização do trabalho real. "Isso faz com que os trabalhadores dos vários níveis hierárquicos 'trapaceiem', 'encubram' as falhas existentes no planejamento do seu trabalho, para que este possa acontecer. É esta trapaça 'inevitável' que está no centro da interface trabalho-saúde mental. O problema, da perspectiva dos trabalhadores, é o status desses 'rearranjos necessários'. No plano subjetivo, a ‘trapaça necessária’ é o que mobiliza a inteligência astuciosa, é onde o trabalhador contribui com sua experiência para que o trabalho aconteça, portanto, é o que torna o trabalho interessante. A arte da trapaça estaria, assim, no âmago do prazer no trabalho, mas, para que esta dinâmica funcione, é necessário relações de confiança entre os operadores e a administração, o que faz com que a trapaça, mais do que simplesmente tolerada, seja reconhecida como necessária [...]. A defasagem existente entre o trabalho prescrito e o real e a “necessidade das 'trapaças' - que poderiam ser a 'fatia nobre do trabalho', pois implicaria uma responsabilidade técnica e humana real dos trabalhadores - transforma-se em fonte de conflito, de desestruturação das relações de cooperação, chegando mesmo a provocar desconfiança. Os operadores passam a desconfiar do chefe, depois, das demais equipes de trabalho, por fim, dos colegas da própria equipe. As relações entre trabalhadores tornam-se tensas, com possibilidade de degeneração a cooperação e a solidariedade desaparecem" (DEJOURS, 2004, p. 245-7).

Para a PDT, esta defasagem entre o trabalho prescrito e o real é fonte de sofrimento psíquico pela solidão à qual ela condena o trabalhador e pela impossibilidade que cria de dar visibilidade ao trabalho, compartilhar responsabilidades e de estabelecer mecanismos de cooperação.

Para Dejours (1997, p. 52), a visibilidade no trabalho é essencial para a compreensão da engenhosidade dos operadores. "a engenhosidade e os artifícios não são facilmente acessíveis à observação do outro. Primeiro, por se tratarem de uma única parte de um ato técnico mais amplo que, separada do conjunto no qual está incluída, nem sempre é facilmente demonstrada [...] por vezes, nem sempre é reconhecida conscientemente pelo próprio sujeito. Os ergonomistas já demonstraram que a inteligência e a habilidade desenvolvidas pelos operadores estão muitas vezes à frente da própria consciência que eles têm delas".

A visibilidade do trabalho realizado é uma condição necessária aos processos de reconhecimento no trabalho. A retribuição e o reconhecimento esperado pelo sujeito é, fundamentalmente, de natureza simbólica - o reconhecimento. O reconhecimento, explica o autor, tem duas dimensões: aquela da contribuição do sujeito à organização do trabalho e a da gratidão por seu esforço em fazer acontecer a organização do trabalho (DEJOURS, 2000). Reconhecer o trabalho dos operadores implica, ao mesmo tempo, reconhecer as falhas da organização do trabalho prescrito e a falta de recursos que os trabalhadores possuem para fazer funcionar todo o processo.

Entendemos que o trabalho é um dos principais alicerces da constituição da identidade de quem o executa. A identificação com o cliente, com os pares, 
com a empresa e com a atividade, são elementos chaves na constituição desta identidade, que por sua vez se reflete na qualidade e na satisfação do trabalho realizado. Neste sentido, a pouca visibilidade e falta de reconhecimento acima apontadas acabam interferindo diretamente neste processo e na saúde mental dos operadores.

\section{CONCLUSÃO}

A PDT busca promover avanços teóricos e metodológicos que desenvolvem seu campo de ação na saúde do trabalhador. Assim, as intervenções procuram facilitar, entre os trabalhadores, a construção de um processo de reflexão sobre o próprio trabalho, permitindo uma apropriação e uma emancipação que conduzam a uma reconstrução coletiva do trabalho e que transformam a prevenção de adoecimentos.

Dejours (1999) propõe, então, o exercício da reflexão coletiva, que supõe mais que uma discussão em conjunto, mas uma ação visando a apropriação de uma inteligibilidade comum, regida pela intercompreensão de acordos e normas, pela produção de novas regras do trabalho e da profissão. É necessário, portanto, a criação de um espaço público de deliberação, onde as pessoas possam falar e se escutar, para que a transformação da organização do trabalho ocorra. A confrontação de opiniões vai ter, assim, o poder de desenvolver a capacidade das pessoas de pensarem individual e/ou coletivamente.

A ação em PDT é ligada à idéia da ampliação do espaço público de deliberação e a uma maior mobilização dos trabalhadores para que eles mesmos possam operacionalizar mudanças. Ou seja, a intervenção permite ampliar a participação dos trabalhadores em ações deliberativas, nas decisões sobre situações de trabalho, numa maior possibilidade de colaborarem com sua inteligência e saber-fazer nos processos de trabalho e na diminuição da defasagem existente entre a planificação e a execução do trabalho.

A organização do trabalho é um compromisso negociado entre quem o organiza e quem o faz. Ela evolui e se transforma. Ela é freqüentemente pensada pelos trabalhadores dos diversos níveis hierárquicos a partir da compreensão que eles têm de seu próprio trabalho, sem que um consiga entender as dificuldades e a racionalidade que rege a prática dos outros. É necessário tornar visíveis as razões, a racionalidade, o sentido do trabalho, a problemática vivida pelos trabalhadores para realizar sua atividade e porque (pelo quê) eles buscam respostas para si próprios e para os outros trabalhadores e demais níveis hierárquicos.
Se o trabalhador é capaz de pensar o trabalho, de elaborar essa experiência ao falar, de simbolizar o pensamento e chegar a uma interpretação, ele tem a possibilidade de negociar, de buscar um novo sentido partilhado, de transformar e fazer a organização do trabalho evoluir.

\section{A AÇÃO EM TERAPIA OCUPACIONAL}

A Psicodinâmica do trabalho tem trazido avanços para a Terapia Ocupacional ao levá-la a considerar os aspectos subjetivos envolvidos nos processos de intervenção em situações de trabalho, de atendimento, de reabilitação e de reinserção no trabalho. É nessa perspectiva que buscamos a constituição de um modelo em Terapia Ocupacional, no campo da Saúde e Trabalho, que subsidie os terapeutas ocupacionais a relacionarem o processo e a organização do trabalho com o adoecimento, o tratamento de doenças ligadas ao trabalho e a reinserção dos afastados por restrições laborais. Para isso, é necessário estar atento à complexidade dos fatores envolvidos no trabalho e no trabalhar (LANCMAN, 2004b).

Os terapeutas ocupacionais buscam, em suas práticas em saúde e trabalho, prevenir adoecimentos, tratar, reabilitar e criar condições para o retorno de pessoas afastadas por adoecimentos ligados ao trabalho. Para isso, eles agem na prevenção, no tratamento e na recuperação de capacidades que foram diminuídas pelos constrangimentos gerados pelas exigências do trabalho.

Não integrar ao processo de reinserção mudanças nas condições de trabalho é expor o trabalhador a novos adoecimentos e à fragilidade das políticas de reinserção e transformar a volta ao trabalho, por vezes, numa exclusão tardia. As práticas em saúde do trabalhador, ao não considerarem as condições e a organização do trabalho como elementos importantes do processo de adoecimento e não se preocuparem com a reintegração no trabalho podem ser danosas porque, além de não ajudarem o indivíduo, colocam nele a responsabilidade pelo sucesso de sua reinserção, culpando-o pelo fracasso, por vezes datado para ocorrer.

Pensar a Terapia Ocupacional pelos princípios teóricos e metodológicos da PDT é considerar que o campo da Saúde e Trabalho deve levar em conta os fatores subjetivos envolvidos no processo de adoecimento, no tratamento e na volta ao trabalho e compreender as implicações subjetivas das exigências do trabalho nesses processos (LANCMAN, 2004b).

Estudar o hiato existente entre as condições dos trabalhadores e as exigências do trabalho que eles enfrentarão é refletir sobre os aspectos subjetivos do 
trabalho, os constrangimentos psíquicos com os quais os indivíduos irão se deparar e que dificultarão ou inviabilizarão o processo de reinserção. Entre os constrangimentos psíquicos, destacamos o preconceito, as estratégias defensivas dos colegas frente ao próprio medo de adoecer, a defasagem entre o trabalho prescrito e o trabalho real, a invisibilidade dos esforços que o trabalhador faz para realizar suas tarefas, a falta de cooperação e o isolamento aos quais todos estão submetidos.

Repensar a ação em Terapia Ocupacional no campo da Saúde e Trabalho é transformar o conceito de ação nas situações de trabalho, de tratamento e de reinserção no trabalho, tornando-os processos ativos para que os indivíduos possam refletir sobre o próprio trabalho para mudar sua relação com o mesmo.

LANCMAN, S., JARDIM, T. A. The work organization impact at the mental health: a phsycodynamic study. Rev. Ter. Ocup. Univ. São Paulo, v. 15, n. 2, p. 82-9, maio/ago., 2004.

\begin{abstract}
S: Starting from the principles of the theory and methodology of the Psychodynamic of the Work this study seek to analyze the impact of the mental health of the Central Operational Center's workers from the Engineer Transit Company of the city of Sao Paulo. To do so, group interventions were performed focusing into reflection about working and to improve the public forum of discussion. The group encounters revealed subjective aspects that could be generating high levels of suffering and sickness. Among the results, we were able to pick several situations where the workers had: a lack of recognition at their tasks, needs of high levels of decisions make impact that directly reflected at the city traffic flow, lack of worker's autonomy without the necessary knowledge of the global situation which they should be interfering and also the disruption of the coworkers mechanism cooperation.
\end{abstract}

KEY WORDS: Mental health. Work/psychology. Occupational psychology. Occupational Therapy.

\section{REFERÊNCIAS}

BANDT, J.; DEJOURS, C. O.; DUBAR, C. La France malade du travail. Paris: Bayard, 1995.

DANIELlOU, F. (Org.) A ergonomia em busca de seus princípios: debates epistemológicos. São Paulo: Edgard Blucher, 2004.

DEJOURS, C. A banalização da injustiça social. Rio de Janeiro: Fundação Getúlio Vargas, 1999.

DEJOURS, C. Novas formas de organização do trabalho e lesões por esforços repetitivos (LER): abordagem através da psicodinâmica do trabalho. In: SZELWAR, L.; ZIDAN, L.(Orgs.). O trabalho humano com sistemas informatizados no setor de serviços. São Paulo: Plêiade, 2000. p. $37-44$

DEJOURS, D. Addendum, da psicopatologia à psicodinâmica do trabalho, In: LANCMAN, S.; SZNELWAR, L. I. (Orgs.). Christophe Dejours: da psicopatologia à psicodinâmica do trabalho. Brasília: Paralelo15/FIOCRUZ, 2004a. p. 47-104.

DEJOURS, D. A metodologia em psicopatologia do trabalho, In: LANCMAN, S.; SZNELWAR, L. I. (Orgs.). Christophe Dejours: da psicopatologia à psicodinâmica do trabalho.
Brasília: Paralelo15/FIOCRUZ, 2004b. p. 105-126.

LANCMAN, S.; MARQUES, M. N.; SIQUEIRA, A. R.; UDIHARA, M.L. Trabalho e saúde: em busca de uma nova relação. Relatório da Intervenção realizada na Companhia de Engenharia de Tráfego de São Paulo. São Paulo, 2002. Mimeografado.

LANCMAN, S.; GHIRARDI, M. I. G. Pensando novas práticas em terapia ocupacional, saúde e trabalho. Rev. Ter. Ocup. Univ. São Paulo, São Paulo, v. 13, n. 2, p. 44-50, 2002.

LANCMAN, S.; UCHIDA, S. Trabalho e subjetividade. Cad. Psicol. Soc. Trabalho, São Paulo, v. 6, p. 77-88, 2003.

LANCMAN, S.; SZNELWAR, L. I. (Orgs.). Christophe Dejours: da psicopatologia à psicodinâmica do trabalho. Brasília: Paralelo15/FIOCRUZ, 2004 (a).

LANCMAN, S. Saúde mental e trabalho: repensando a ação em terapia ocupacional. 2004. Tese (Livre-docência)Faculdade de Medicina, Universidade de São Paulo. São Paulo, 2004b. 